\title{
Counterfactual Attitudes and the Relational
}

\section{Analysis}

\author{
Kyle Blumberg \\ New York University \\ Penultimate draft
}

\begin{abstract}
In this paper, I raise a problem for standard precisifications of The Relational Analysis. The problem I raise involves so-called 'counterfactual' attitude verbs, such as 'wish'. In short, the trouble is this: there are true attitude reports ' $S$ wishes that $\mathrm{P}$ ' but there is no suitable referent for the term 'that P'. The problematic reports illustrate that the content of a subject's wish is intimately related to the content of their beliefs. I capture this fact by moving to a framework in which 'wish' relates subjects to sets of pairs of worlds, or paired propositions, rather than — as is standardly assumed - sets of worlds. Although other types of counterfactual attitude reports, e.g. those involving 'imagine', may be similarly problematic, at this stage it is unclear whether they can be handled the same way.
\end{abstract}




\section{Introduction}

Many philosophers and linguists endorse the Relational Analysis of attitude reports: ${ }^{1}$

The Relational Analysis: where $\Phi$ is an attitude verb, ' $S \Phi$ s that $\mathrm{P}$ ' is true just in case the referent of $S$ bears the relation expressed by $\Phi$ to the proposition expressed by $\mathrm{P}$.

According to the Relational Analysis, 'John believes that Peter is bald' is true just in case John is 'belief'-related to the proposition that Peter is bald, and 'John knows that Peter is bald' is true just in case John is 'knowledge'-related to the proposition that Peter is bald, and 'John hopes that Peter is bald' is true just in case John is 'hope'-related to the proposition that Peter is bald, etc.

The Relational Analysis has much going for it. For one thing, it is intuitively plausible. For instance, it seems obvious that 'Bill believes that Joan is in the basement' is true iff Bill stands in the belief relation to the proposition that Joan is in the basement. For another, it provides an elegant account of the validity of inferences such as the following:

(I) Andrew believes that Joan is in the basement.

(II) Ben believes that Joan is in the basement.

(C) There is something that both Andrew and Ben believe.

The Relational Analysis is schematic. It leaves open the nature of the relation picked out by 'belief', 'know', 'hope', etc. It also leaves open the nature of the proposition expressed by, say, 'Peter is bald'. In this paper, I present a problem for standard precisifications of the Relational Analysis. ${ }^{2}$ The problem I raise

\footnotetext{
${ }^{1}$ In the philosophical literature, see e.g. (Stalnaker, 1988) and (Schiffer, 2003). The analysis is also widely accepted among semanticists, see e.g. (von Fintel \& Heim, 2011, ch.2).

${ }^{2}$ In fact, I raise a problem for a weaker principle, namely the claim that ' $S \Phi$ s that $\mathrm{P}$ ' is true only if (i) the referent of $S$ bears the relation expressed by $\Phi$ to the proposition expressed by $\mathrm{P}$, or (ii) the referent of $S$ bears the relation expressed by $\Phi$ to a proposition suitably related
} 
involves so-called 'counterfactual' attitude verbs, such as 'wish'. In short, the trouble is this: there are true reports ' $S$ wishes that $\mathrm{P}$ ' but there is no suitable proposition that can be the referent of the term 'that P'. I show that common ways of resolving ambiguities that arise because of the interaction between determiner phrases (DPs) and intensional operators, e.g. de dicto readings and de re readings, do not yield appropriate propositions.

The problematic reports illustrate that the content of a subject's wish is intimately related to the content of their beliefs. I capture this fact by moving to a framework in which 'wish' relates subjects to sets of pairs of worlds, or paired propositions, rather than — as is standardly assumed — sets of worlds. Roughly put, the idea is that the first element in the ordered pair will be tied to the subject's beliefs, while the second will be tied to their preferences, or wishes, relative to their beliefs. Although other types of counterfactual attitude reports, e.g. those involving 'imagine', may be similarly problematic, at this stage it is unclear whether they can be handled in the same way. ${ }^{3}$

The paper is structured as follows. In $\S 2$ I introduce the problem. $\S 3$ specifies the framework in which the discussion will be set, namely a possible worlds semantics. A solution to the problem is sought in $\S 4$ by considering various readings of the relevant report, while in $\S 5$ I consider a response that appeals to 'actualized' propositions. A positive proposal is presented, and defended, in $\S 6$. $\S 7$ concerns the semantics of counterfactual attitude verbs other than 'wish'. Finally, in $\S 8$ I discuss whether paired propositions allow us to preserve a version of the Relational Analysis.

to the proposition expressed by P. Many critics of the Relational Analysis, e.g. Crimmins \& Perry (1989) and Graff Fara (2013), endorse this weaker claim. I return to this point briefly in $\S 9$.

${ }^{3}$ Ninan (2008) develops, but ultimately rejects, a semantics for de re imagination reports that makes use of paired propositions. This semantics is discussed in $\S 7$. 


\section{The problem}

Consider the following scenario:

Burgled Bill: It's Saturday morning, and Bill wakes up to find that the window of the back-door of his house has been smashed, with a trail of muddy footprints leading to his study. Fearing the worst, he runs to his study to check on his safe. He discovers the safe door open, and the safe emptied of its contents. His valuable collection of silverware is nowhere to be found. Given all of the evidence, Bill is quite certain that he's been burgled, and that the perpetrator acted alone. As it happens, Bill wasn't robbed. His wife removed the silverware from the safe so that it could be cleaned; a confused bird flew into the window pane and smashed it; and the muddy footprints belonged to Bill — he made them unknowingly the night before. After calling the police, Bill sits at his kitchen table with his head in his hands and says 'I wish that the person who robbed me had never robbed anyone'.

I submit that the following sentence is true in the context of Burgled Bill:

(1) Bill thinks that somebody robbed him, and he wishes that the person who robbed him had never robbed anyone.

In particular, the second conjunct is true:

(2) Bill wishes that the person who robbed him had never robbed anyone.

Here is the problem: according to the Relational Analysis, (2) is true only if Bill stands in the relation expressed by 'wish' to a suitable proposition. But what proposition could this be? In $\S 4$ I show that standard ways of resolving familiar ambiguities that arise when definite descriptions occur in the scope of propositional attitude verbs do not yield appropriate semantic values for the that-clause. Let me summarize those arguments here so that the reader immediately has a sense of the challenge. 
On the de dicto reading of (2), the object of Bill's wish takes the form 'The $F$ never Fed'. This has Bill wishing something that is obviously logically incoherent, which badly misrepresents Bill's desires. Hence, (2) can't be read de dicto.

Moreover, the report cannot be read de re since a natural de re paraphrase of (2) is 'there is a person $x$ who uniquely robbed Bill and is such that Bill wishes that $x$ had never robbed anyone'. This can't be true for the simple reason that nobody robbed Bill.

Finally, the denotation of 'the person who robbed Bill' can't be a particular entity — either existent or non-existent — who Bill thinks robbed him, for (2) is true even when Bill is unsure who robbed him, and has several suspects.

\section{A framework}

As mentioned in $\S 1$, the Relational Analysis is schematic. It leaves open the nature of the relation picked out by 'belief', 'know', 'wish', etc., and it also leaves open what propositions are. I argue that (2) raises difficulties for standard precisifications of the Relational Analysis. Although my conclusion is general, I will not consider every such precisification. Instead, I focus my discussion on the most popular way of fleshing out the Relational Analysis in the formal semantics literature. In this section, I briefly present the framework that I will be working in.

On the approach under consideration, propositions are sets of possible worlds or, what amounts to the same thing, characteristic functions of such sets. Where $\phi$ is a declarative sentence, the proposition expressed by $\phi$ is the set of worlds in which $\phi$ is true. ${ }^{4,5}$ For example, the proposition expressed by 'Peter is bald'

\footnotetext{
${ }^{4}$ This is rough because it doesn't take indexicality into account. We can harmlessly ignore such complications here.

${ }^{5}$ On this approach, sentences that are true in the same worlds but are 'gappy' at different
} 
is the set of worlds in which 'Peter is bald' is true. ${ }^{6}$

What relations do attitude verbs denote? In a tradition that begins with Hintikka (1962), many attitude verbs have a quantificational semantics involving a lexically-determined accessibility relation. For instance, relative to a world $w$, 'believe' denotes a relation that holds between an agent $S$ and a proposition $p$ just in case every world compatible with $S$ 's beliefs in $w$ is a $p$-world. On this approach, 'Bill believes that Ann left' is true at world $w$ just in case every world compatible with what Bill believes in w - every world in Bill's belief set in $w$ - is one where Ann left.

It is tempting to treat 'wish' similarly, i.e. as a function such that 'Bill wishes that Ann had left' is true at world $w$ just in case every world that conforms to what Bill wishes in $w$ - every world in Bill's wish set in $w$ - is one where Ann left. However, Heim (1992) showed that this meaning for 'wish' is unsatisfactory. In $\S 6$ I discuss Heim's arguments and incorporate her insights into my positive proposal. For now, we need only assume that 'wish' denotes some relation which we will leave unspecified - to propositions.

\section{De dicto, de re, and 'merely specific' readings}

Now that we have a precisification of the Relational Analysis before us, I can be more precise about why the truth-conditions of (2) can't be understood to involve Bill being 'wish'-related to a suitable proposition (where 'proposition' is conceived as a set of worlds). It is well known that there are ambiguities

worlds express the same proposition. Although one might want to draw a distinction here for many purposes, doing so isn't necessary for my aims.

${ }^{6}$ Strictly speaking, few theorists think that propositions are sets of worlds. For instance, some theorists think that worlds are too coarse-grained and employ situation structures instead (e.g. Elbourne (2013)). In order to capture de se phenomena, others use centered worlds (e.g. Lewis (1979)); and Ninan (2012) uses multi-centered worlds to handle the problem of counterfactual de re attitudes (see $\S 6.5$ for a discussion of this puzzle). It will be clear how the problem raised by (2) applies to any theory that employs truth-supporting circumstances of some sort or another, so I've opted for a simpler account that involves center-less worlds. 
that arise when DPs (such as definite descriptions) interact with intensional operators. It might be supposed that resolving these ambiguities will yield an appropriate reading of (2). However, this thought is mistaken.

Let us begin with the de dicto/de re ambiguity. For simplicity, let us suppose that this ambiguity is taken to be an ambiguity of scope. De dicto readings are represented by supposing that the relevant DP is within the intensional operator's complement at logical form (LF); whereas de re readings are represented by supposing that the DP is raised to a position above the intensional operator at LF. ${ }^{7}$ Thus, the de dicto reading of (2) becomes

Bill wishes [the person-who-robbed-Bill never-robbed-anyone]

And the de re reading is

(4) [the person-who-robbed-Bill] $\lambda x_{1}$ Bill wishes $x_{1}$ never-robbed-anyone ${ }^{8}$

Neither (3) nor (4) captures the appropriate reading of (2). On any reasonable semantics for 'the', (3) is true only if Bill is 'wish'-related to a set of worlds such that for every world $w$ in that set, a unique person who robbed Bill at $w$ never robbed anyone at $w$. But no world is such that a unique person who robs Bill at that world never robs anyone. In other words, (3) has Bill wishing the impossible proposition. However, Bill's wish does not appear to be equivalent to wishing that somebody was not self-identical, or that the laws of logic were different. Thus, the de dicto reading of (2) misrepresents Bill's wish. ${ }^{9}$

Just to be clear, I do not deny that subjects can coherently wish-true impossible propositions. For example, Harry might reasonably wish that Fermat's

\footnotetext{
${ }^{7}$ See (Heim \& Kratzer, 1998, 184-188) for more on this sort of raising.

${ }^{8}$ The lambda binder ' $\lambda$ ' is a device for forming predicates from open formulas. For instance, given an open formula ' $F x$ ', ' $\lambda x F x$ ' is a one-place predicate.

${ }^{9}$ Strictly speaking, on a Fregean semantics for 'the', the complement of (3) expresses a partially defined, or 'gappy' proposition. But this doesn't make the de dicto reading of (2) any more plausible. That (3) is problematic no matter which analysis we give the definite determiner (either Russellian or Fregean) shows that the puzzle raised by (2) is distinct from the 'existence problem' for Russellians that has recently been discussed by Schoubye (2013) and Elbourne (2013).
} 
last theorem had been false (perhaps he is jealous of Andrew Wiles). However, the problem posed by (2) seems distinct from the problem of logical omniscience (or 'logical omni-wishing'). Furthermore, in no obvious way can the resources used in attempts to solve the latter be employed to defuse the former. For instance, in $\S 5 \mathrm{I}$ consider an appeal to structured propositions and argue that their application to the puzzle posed by (2) faces difficulties.

As for (4), this will be true only if there exists a unique person who robbed Bill. But nobody robbed Bill, so (4) cannot be true. In short, de re readings are existentially committing, so (2) cannot be read de re.

It might be thought that (2) could be captured by allowing the description 'the person who robbed Bill' to denote someone who is merely thought by Bill to have robbed him, regardless of whether they actually committed a crime. Let us call this a 'merely specific' reading of (2). The major problem with this proposal is that it is simply not the case that Bill needs to believe that a particular person, or even a particular entity that is not a person, robbed him in order for (2) to be true. ${ }^{10}$ For instance, suppose that Bill isn't sure who robbed him, but he thinks that the culprit is either Joe or Steve. That is, there are worlds $w_{1}$ and $w_{2}$ in Bill's belief set such that Joe robs Bill at $w_{1}$ and Steve robs Bill at $w_{2}$. In this scenario, (2) is still true, but it is false on a merely specific reading.

\section{Actualized propositions}

We have employed a possible worlds framework to precisify the Relational Analysis. But it should be clear that the difficulties discussed thus far also arise for other popular ways of interpreting 'proposition'. In particular, views on which propositions are structured entities don't make the de dicto or de re readings

${ }^{10}$ See (Salmon, 1998) for a discussion of 'mythical' objects. 
of (2) any more plausible. On this conception, propositions are complex structures that have constituents, or parts, that are bound together in a certain way. The simplest account of structured propositions maintains that they are ordered tuples ultimately built up of objects, properties, and relations. ${ }^{11}$

However, the structured propositionalist might have another way of handling the problem. The general idea is that the proposition that Bill wishes true is 'actualized' in some manner. On this proposal, (2) can be paraphrased as 'Bill wishes that the person who actually robbed him had never robbed anyone'. It could be argued that the reasonableness of Bill's wish is accounted for, since Bill happens not to know that nobody actually robbed him; for the same reason that he doesn't know that nobody robbed him. ${ }^{12}$

On one way of implementing this idea, it is maintained that the operator @ is a constituent of the proposition that Bill wishes true. Semantically, this operator indexes expressions in its scope to the actual world, e.g. 'person who robbed Bill. ${ }^{13}$ Alternatively, it might be maintained that the proposition that Bill wishes true contains the actual world $w_{@}$ as a constituent. ${ }^{14}$

Notice, however, that neither @ nor w@ can always be a constituent of the proposition that Bill wishes true. Suppose that Bill knows that he wasn't robbed, and consider (5) and (6), which can both be true at the actual world:

(5) If Bill had wrongly believed himself to have been robbed, he would have wished that the person who robbed him had never robbed anyone.

(6) It might have been that: Bill wrongly believed himself to have been robbed, and he wished that the person who robbed him had never robbed anyone.

\footnotetext{
${ }^{11}$ See (King, 2014) for more.

${ }^{12}$ It is important that this 'actualizing' move is done in a structured setting. Given that nobody robbed Bill, the semantic value of 'the person who actually robbed Bill never robbed anyone' is the impossible/undefined proposition on the worlds framework.

${ }^{13}$ On this account, a simplified representation of the proposition expressed by the prejacent in $(2)$ is $\langle\langle$ the $\langle @$, person who robbed Bill $\rangle\rangle$, never robbed anyone $\rangle$.

${ }^{14}$ On this account, a simplified representation of the proposition expressed by the prejacent in $(2)$ is $\left\langle\left\langle\right.\right.$ the $\left\langle\right.$ in, $w_{@}$, person who robbed Bill $\left.\rangle\right\rangle$, never robbed anyone $\rangle$.
} 
Focusing on (5), it is implausible that if Bill had wrongly believed himself to have been robbed, he would have wished that the person who actually robbed him had never robbed anyone, or that the person who robbed him at w@ had never robbed anyone. If anything, counterfactual Bill wishes that the person who counterfactually robbed him, or the person who robbed him at the relevant counterfactual world, never robbed anyone. ${ }^{15}$

What (5) and (6) show is that the structured propositionalist needs to allow that either (i) the operator that features in the complement of the report can shift the evaluation function to worlds other than the actual world when embedded under higher operators; or (ii) the world that features in the proposition that Bill wishes true can vary appropriately. However, regarding (i) it is completely unclear what would be required in order to hold an attitude towards a proposition that contained such an operator as a constituent. Moreover, it is unclear what a compositional semantics that incorporated (ii) would look like. Developing such an account appears to be a considerable challenge. By contrast, my positive proposal is compositional, and can handle embedded reports.

\section{A semantics for 'wish'}

So far, my points have been critical: I have argued that wish reports pose a problem for the Relational Analysis. In this section, I provide a compositional semantics for 'wish' and discuss the issues which it raises. My positive account is built on two technical developments. I present each in turn, starting with Heim (1992)'s semantics for desire-based attitudes.

\footnotetext{
${ }^{15}$ There also exist arguments which imply that counterfactual Bill can never wish true a proposition that contains either @ or $w_{@}$. These are given by Soames (2002, 39-47), Braun (2008, 351-353) and others. The general idea is that normal subjects at counterfactual worlds cannot think, wish, desire, etc. things about the actual world, since they are not acquainted, or epistemically connected, to the actual world. However, epistemic constraints of this sort are controversial (see (Hawthorne \& Manley, 2012) for discussion).
} 


\subsection{Heim's semantics}

In $\S 3$ I mentioned that the Hintikka-style semantics for 'wish' is problematic. Let me expand on this here. Suppose that Bill plays a game where two fair coins are flipped. He wins a big prize if both coins come up heads, and a small prize if both coins come up tails. In any other event he wins nothing. As it happens, both coins land tails. Now consider (7) and (8):

(7) Bill wishes that both coins landed heads.

(8) Bill wishes that the second coin landed heads.

(7) does not entail (8). However, if every world in Bill's wish set is one where both coins land heads, then it follows that every world in his wish set is one where the second coin lands heads. So, on a Hintikka-style semantics (7) does entail (8). Notice that the issue here is distinct from the problem of logical omniscience, since it is plausible that 'Bill believes that both coins landed heads' does entail 'Bill believes that the second coin landed heads'. Rather, the problem arises because 'wish' is non-monotonic over relevant logical consequences.

Heim makes another, closely related point: the Hintikka-style semantics gets even simple cases such as (9) wrong:

(9) John wishes he had taught on Tuesdays.

Heim notes that (9) can be true even if every world compatible with everything that John wishes is such that he does no teaching at all. However, in such a situation the Hintikka-style semantics makes the sentence come out false.

In response to these difficulties, Heim moves away from the Hintikka-style semantics, and sees wish reports as employing a notion of comparative desirability. The general idea is that wish reports are true when subjects prefer worlds in which the thing being wished for holds to worlds in which it doesn't. To 
make this more precise, let us say that for any subject $S$ and world $w$, Dox ${ }_{w, S}$ is the set of worlds compatible with what $S$ believes in $w$, i.e. $S$ 's belief set in $w$. Then ' $S$ wishes $p$ ' is true at $w$ when, for each $w$ ' in $\operatorname{Dox}_{w, S}: S$ prefers each world most similar to $w^{\prime}$ in which $p$ holds, to any world most similar to $w^{\prime}$ in which $p$ does not hold.

On this account, (9) is true at $w$ so long as, for each $w^{\prime}$ in $\operatorname{Dox}_{w, J o h n}$ : John prefers each world most similar to $w^{\prime}$ in which he teaches on Tuesdays to any world most similar to $w^{\prime}$ in which he does not. ${ }^{16}$ Importantly, John might have this preference even though every world compatible with everything that John wishes at $w$ is such that he does no teaching at all. Moreover, Bill can prefer closest worlds in which both coins land heads to closest worlds in which they do not, even if he does not prefer closest worlds in which the second coin lands heads to closest worlds in which it does not. Thus, this semantics improves on the Hintikka-style entry described in $\S 3$.

It will be helpful to modify the account slightly before moving on. Reports such as (9) require that subjects believe that the prejacent is false, i.e. each $w^{\prime}$ in $\operatorname{Dox}_{w, S}$ is a world in which $p$ does not hold. ${ }^{17}$ Given the assumption of Strong Centering (Lewis, 1973), i.e. the assumption that the closest $q$-world to a world $w$ in which $q$ holds is simply $w$, Heim's semantics is represented in (10):

(10) ' $S$ wishes $p$ ' is true at $w$ when, for each $w^{\prime}$ in $\operatorname{Dox}_{w, S}$ : for all worlds $w^{\prime \prime}$ which are as similar as possible to $w^{\prime}$ in which $p$ holds, $S$ prefers $w^{\prime \prime}$ to $w^{\prime} .^{18}$

\footnotetext{
${ }^{16}$ Heim only considers the worlds closest to those in Dox $w$,John because (9) can be true even if, for instance, John disprefers some distant worlds in which he taught on Tuesdays (e.g. where the human race is enslaved by cruel aliens) to some worlds in which he does not. As in standard semantics for counterfactual conditionals, the notion of similarity employed here shouldn't necessarily be expected to track what we would normally mean by 'similar'. See (Lewis, 1979) for discussion, as well as fn.26 below.

${ }^{17}$ These reports are in the irrealis mood (Heim, 1992, 217, fn.35).

${ }^{18}$ Heim's entry is given in the context of a dynamic semantics. I get the static version from Villalta $(2008,475)$. Villalta refines Heim's semantics in various ways - see Rubinstein (2012, ch.3) for discussion. Although I think that some of the refinements are well motivated, they're orthogonal to our present concerns. So, I stick with something closer to Heim's original proposal.
} 
Note that the points raised above extend beyond the verb 'wish': there are other attitudes for which a Hintikka-style semantics is inappropriate, e.g. 'want'. 'want' is also non-monotonic over relevant logical consequences: 'Bill wants to buy discounted plane tickets' does not entail 'Bill wants to buy plane tickets'. Moreover, a report such as 'Bill wants to teach on Tuesdays next semester' can be true even if every world compatible with everything that Bill desires is such that he does no teaching at all. In general, desire-based attitudes involve a preference over alternatives. Let us call such attitudes non-representational; and other attitudes representational. ${ }^{19}$ We will return to the distinction between representational and non-representational attitudes in $\S 7$.

\subsection{World variables}

In order to motivate the second piece of machinery needed for my positive account, let us reflect for a moment on Bill's wish in Burgled Bill. Intuitively, his wish can be characterized as follows: he believes that someone robbed him, and he feels that it would have been better if that person had never robbed anyone. So, it appears that we could get the right reading for (2) if we interpret 'the person who robbed Bill' relative to each of Bill's belief worlds, and then 'run' Heim's semantics on the result. In that case, (2) will be true at $w$ iff for each of Bill's belief worlds $w^{\prime}$ : Bill prefers each world most similar to $w^{\prime}$ in which the person who robbed Bill at $w^{\prime}$ never robbed anybody, to $w^{\prime}$. I take these to be our target truth-conditions.

The crucial idea in presenting the above truth-conditions is that the denotation of 'the person who robbed Bill' is allowed to vary with the choice of belief world $w^{\prime}$. How do we capture this thought? Here is a suggestion. Intuitively, for each of Bill's belief worlds $w^{\prime}$, we want to generate a set of worlds: the worlds

\footnotetext{
${ }^{19}$ Although not all theorists use the same terminology, many have proposed a semantic split between desire-based attitudes and the rest. See, for example, (Bolinger, 1968), (Stalnaker, 1984), and (Farkas, 1992).
} 
in which the person who robbed Bill at $w^{\prime}$ never robbed anyone. That is, we need to appeal to a function $p^{*}$ from Bill's belief worlds to sets of worlds. $p^{*}$ will take one of Bill's belief worlds $w^{\prime}$ and return the set of worlds in which the person who robbed Bill at $w^{\prime}$ never robbed anyone. $p^{*}$ can be used to express the truth-conditions of (2) as follows: (2) is true at $w$ iff for each of Bill's belief worlds $w^{\prime}$ : Bill prefers each world in $p^{*}\left(w^{\prime}\right)$ which is as similar as possible to $w^{\prime}$, to $w^{\prime}$.

A function from a world $w^{\prime}$ to a set of worlds can also be represented as a set of pairs $\left\langle w^{\prime}, w^{\prime \prime}\right\rangle$. So, let us call $p^{*}$ a paired proposition. Rather than model the content of Bill's wish through sets of worlds, let us model it through paired propositions.

Now the question is: how do we incorporate paired propositions in a compositional semantics for 'wish'? I propose that we build on the approach that posits world variables in the syntax. World variables were introduced as an alternative to scopal accounts of the de dicto/de re distinction. They were designed to get the relevant readings without movement, and solve other problems as well. ${ }^{20}$ The idea is that each predicate at LF is assigned an index $-w_{i}$, where $i$ is a natural number - that indicates the world relative to which the predicate is to be evaluated. For instance, teacher $_{w_{7}}$ indicates that the predicate 'teacher' should be evaluated at world $w_{7}$. Thus, when we evaluate teacher $_{w_{7}}$ we will get the set of teachers at $w_{7}$.

To get a feel for how the system works, here is how the de dicto reading (11) and the de re reading (12) of 'Bill believes that the person who robbed him dances' would be captured:

(11) $\lambda w_{1}$ Bill believes $w_{1}\left[\lambda w_{2}\left[\right.\right.$ the person-who-robbed-Bill $w_{w_{2}}$ dances $\left.\left._{w_{2}}\right]\right]$

\footnotetext{
${ }^{20}$ See (von Fintel \& Heim, 2011, 102-110) for an introduction to the world variables approach, and (Keshet, 2008) for a more detailed discussion.
} 
$\lambda w_{1}$ Bill believes $_{w_{1}}\left[\lambda w_{2}\right.$ [the person-who-robbed-Bill ${ }_{w_{1}}$ dances $\left.\left._{w_{2}}\right]\right]$

In this system, variable binders appear at the top of sentences, and a sentence, $\phi$, is true at a world, $w$, just in case $\llbracket \phi \rrbracket(w)=1$. When (11) is evaluated at the actual world, w@, only 'believes' is evaluated at w@ (giving us Bill's belief set at $w_{@}$ ) — 'person who robbed Bill' (and 'dances') is evaluated relative to Bill's belief worlds (i.e. those worlds in Bill's belief set at $w_{@}$ ). This gives us the de dicto reading. By contrast, when (12) is evaluated at w@, both 'believes' and 'person who robbed Bill' are evaluated there. The extension of 'person who robbed Bill' at the actual world is the set of people who actually robbed Bill, giving us the de re reading.

\subsection{An entry for 'wish'}

Now let us put things together. By employing Heim's comparative desirability semantics over paired propositions, we have found the correct truth conditions for (2). However, it was unclear how to incorporate these truth conditions in a compositional semantics. In order to solve this problem, let us extend the world variable approach by allowing two variable binders to appear at the top of sentences rather than just one. The sentence inside 'wish' in (2) will then receive the following $\mathrm{LF}$ :

$$
\lambda w_{1} \lambda w_{2} \text { [the person-who-robbed-Bill } w_{1} \text { never-robbed-anyone } w_{2} \text { ] }
$$

The semantic value of (13) is a paired proposition, a function of type $\langle s,\langle s, t\rangle\rangle$. Which function is this? Assuming a Fregean analysis of 'the', it is a function that, given any world $w^{\prime}$ where a unique person robbed Bill, returns the set of worlds where that person never robbed anyone; and the function is undefined at worlds where no unique person robbed Bill. Notice that the paired proposition expressed by (13) is not a constant function; when it is fed a belief world $w^{\prime}$, the result is a set of worlds that in some sense depends on $w^{\prime}$. 
The lexical entry for 'wish' is the following:

$$
\begin{aligned}
& \llbracket w i s h \rrbracket= \\
& \lambda w \in D_{s} . \lambda p^{*} \in D_{\langle s,\langle s, t\rangle\rangle} \cdot \lambda x \in D_{e} . \forall w^{\prime} \in \operatorname{Dox}_{w, x}: \operatorname{Sim}_{w^{\prime}}\left(p^{*}\left(w^{\prime}\right)\right)>_{x, w}\left\{w^{\prime}\right\}
\end{aligned}
$$

This needs some explaining. For any subject $x$ and world $w,>_{x, w}$ is a preference relation between worlds: $w^{\prime}>_{x, w} w^{\prime \prime}$ iff $w^{\prime}$ is more desirable to $x$ in $w$ than $w^{\prime \prime}$. We can also give this an extended sense as a relation between sets of worlds $X \subseteq W, Y \subseteq W: X>_{x, w} Y$ iff $w^{\prime}>_{x, w} w^{\prime \prime}$ for all $w^{\prime} \in X, w^{\prime \prime} \in Y . \operatorname{Sim}_{w^{\prime}}(p)$ is a similarity function that maps propositions to propositions, and takes each proposition $p$ to the set of worlds maximally similar to $w^{\prime}$ in which $p$ is true. ${ }^{21}$ So, in words (14) says: where $S$ is a subject and $p^{*}$ is a paired proposition, ' $S$ wishes $p^{*}$ ' is true at $w$ when, for each $w^{\prime}$ compatible with $S$ 's beliefs in $w, S$ prefers the closest $p^{*}$-related worlds to $w^{\prime}$, to $w^{\prime}{ }^{22}$

We give (2) the following LF:

(16) $\lambda w_{1}$ Bill wishes $_{w_{1}}\left[\lambda w_{2} \lambda w_{3}\right.$ the person-who-robbed-Bill $w_{2}$ never-robbed-anyone $\left.w_{3}\right]$

(16) is true at $w @$ just in case for every one of Bill's belief worlds $w^{\prime}$, a unique person robbed Bill at $w^{\prime}$, and every world $w^{\prime \prime}$ that is maximally similar to $w^{\prime}$ in which the person who robbed Bill at $w^{\prime}$ never robbed anyone is such that Bill prefers $w^{\prime \prime}$ to $w^{\prime}$ at $w @$. These were our target truth-conditions; but now we have seen how to derive them compositionally.

\footnotetext{
${ }^{21}$ Both the preference relation and the similarity function are taken directly from Heim. However, the use of paired propositions is novel.

${ }^{22}$ Given Weak Centering ( $w \in \operatorname{Sim}_{w}(p)$ if $\left.w \in p\right)$, on this account ' $S$ wishes $p^{*}$ ' is automatically false when $p^{*}$ relates any of $S$ 's belief worlds to itself. A less restrictive entry (similar to the first version of Heim's semantics considered in §6.1) is given in (15):

(15) $\llbracket w i s h \rrbracket=\lambda w \in D_{s} . \lambda p^{*} \in D_{\langle s,\langle s, t\rangle\rangle} . \lambda x \in D_{e} . \forall w^{\prime} \in \operatorname{Dox}_{w, x}: \operatorname{Sim}_{w^{\prime}}\left(p^{*}\left(w^{\prime}\right)\right)>_{x, w}$ $\operatorname{Sim}_{w^{\prime}}\left(\neg p^{*}\left(w^{\prime}\right)\right)$
} 


\subsection{Overgeneration}

Let me immediately deal with a possible objection to my account. Several semanticists have argued that the world variable approach overgenerates. ${ }^{23}$ In response, proponents of such accounts have put forward particular 'binding constraints' on world variables. However, one might suspect that having an extra binder at the top of sentences embedded under attitude verbs raises a more severe threat of overgeneration.

To motivate constraints on which world variables are assigned to predicates, consider (17):

(17) Bill thinks that my sister sings.

Percus (2000) points out that if there are no constraints, then (17) can receive the following LF:

(18) $\lambda w_{1}$ Bill thinks $_{w_{1}}\left[\lambda w_{2}\right.$ my sister $\left.w_{2} \operatorname{sings}_{w_{1}}\right]$

Simply put, (18) is true at at $w_{@}$ just in case all of the candidates that Bill is considering for being my sister sing (even though Bill needn't believe this). However, (17) cannot have this reading.

In response, Percus (2000) proposes that we forbid certain binding patterns. He puts forward the following constraint, which he calls 'Generalization X':

Generalization $X$ : The world variable that the main verb selects for must be coindexed with the nearest $\lambda$ above it. ${ }^{24}$

Clearly, this blocks the problematic reading of (17), since the world variable selected by 'sings' in (18) isn't coindexed with the nearest $\lambda$ above it.

What I want to point out is that Generalization X suffices to eliminate all the bad readings that my account generates if we imposed no binding constraints. Here are some relevant LFs for (2):

\footnotetext{
${ }^{23}$ E.g. Percus (2000), Keshet (2008), and Romoli \& Sudo (2009).

${ }^{24}$ Percus works with situations rather than worlds. We can safely ignore this difference.
} 
(19) $\lambda w_{1}$ Bill wishes $_{w_{1}}\left[\lambda w_{2} \lambda w_{3}\right.$ the person-who-robbed-Bill $w_{2}$ never-robbed-anyone $\left.w_{3}\right]$

(20) $\lambda w_{1}$ Bill wishes $_{w_{1}}\left[\lambda w_{2} \lambda w_{3}\right.$ the person-who-robbed-Bill $w_{2}$ never-robbed-anyone $\left.w_{1}\right]$

(21) $\lambda w_{1}$ Bill wishes $_{w_{1}}\left[\lambda w_{2} \lambda w_{3}\right.$ the person-who-robbed-Bill $w_{3}$ never-robbed-anyone $w_{2}$ ]

(19) is our preferred LF for (2) (repeated from above). Let us consider (20). Roughly put, on my semantics $(20)$ is true at $w_{@}$ just in case Bill prefers worlds in which the candidates he is considering for being the person who robbed him in fact never robbed him (though Bill needn't believe this). Clearly, (2) has no such reading.

As for (21), its meaning is difficult to get a grip on. Roughly, (21) is true at $w_{@}$ just in case Bill prefers worlds in which a unique person robs him. But (2) cannot have these truth-conditions.

Importantly, Generalization X rules out (20) and (21). In neither case is the world variable that the main verb 'never robbed anyone' selects for coindexed with the nearest $\lambda$ above it. More generally, this suggests that the binding constraints put forward in order stop overgeneration in the simpler system still apply in a framework with multiple binders at the top of sentences. No additional constraints need to be posited..$^{25,26}$

\footnotetext{
${ }^{25}$ Romoli \& Sudo (2009) argue that the need for such constraints in the first place is ad hoc, and poses a problem for the world variable approach. Although I think that the approach can be defended from these worries, I do not intend to do that here. I only claim that there are no additional costs to positing an extra binder.

${ }^{26} \mathrm{An}$ anonymous reviewer poses a different problem for my account. They question whether my semantics can handle the sort of case that was used to undermine the merely specific reading of (2) considered in $\S 4$. In that embellishment of Burgled Bill, Bill is not sure who robbed him, but he thinks that either Joe or Steve did it. Thus, there are worlds in Bill's belief set in which Joe robbed him, and worlds in which Steve robbed him. Let $w_{1}$ be an instance of the former, and $w_{2}$ an instance of the latter. The reviewer suggests that $w_{2}$, a world in which Joe never robbed Bill, is maximally similar to $w_{1}$ since $w_{2}$ is just like $w_{1}$ in containing an event of Bill-robbing, differing only in who did the robbing. However, Bill needn't prefer $w_{2}$ to $w_{1}$ - he might well be indifferent between them.

One response is that similarity is at least in part a contextually determined matter, and
} 


\subsection{Ninan's puzzle}

I am not the first to use paired propositions in a semantics for attitude ascriptions. Indeed, Ninan (2008) developed, but ultimately rejected, an account that made use of these objects. However, Ninan's motivation for introducing paired propositions is distinct from mine. Moreover, the way in which paired propositions are employed in Ninan's (rejected) theory is quite different from the manner in which they are put to use in our lexical entry for 'wish'. In this section, I discuss Ninan's reason for introducing paired propositions, namely his puzzle of 'counterfactual de re attitudes', and how it differs from the problem raised by (2). In $\S 7$ I consider Ninan's two-dimensional semantics, and why it is problematic.

Ninan $(2008,2012)$ raises a challenge for descriptivist accounts of de re ascriptions. Descriptivists maintain that de re belief reports existentially quantify over descriptions, or guises. On this theory, a report such as 'Ralph believes that Ortcutt is a spy' is true just in case there exists an appropriate acquaintance relation $R$ such that Ralph bears $R$ to Ortcutt and Ralph believes that the thing to which he bears $R$ is a spy. ${ }^{27}$ For instance, the relevant acquaintance relation could be the relation that $x$ bears to $y$ just in case $y$ is the unique individual that $x$ sees sneaking around the docks.

Ninan argues that although descriptivism might work in the case of de re belief, it breaks down when we try to extend the account to counterfactual attitudes. Ninan's argument centers on 'imagine', not 'wish'. Although there are important differences between these verbs (see $\S 7$ ), they are not relevant

in the relevant context $w_{2}$ is not most similar to $w_{1}$. Moreover, as discussed in fn.16, the notion of similarity at play in my semantics shouldn't necessarily be expected to track what we would normally mean by 'similar'. This response isn't ad hoc, since an idiosyncratic notion of similarity is needed in other areas, namely in standard semantics for counterfactual conditionals. Indeed, the reviewer's case bears a resemblance to conditionals such as 'If Nixon had pushed the button, there would have been a nuclear war' (Fine, 1975). See (Lewis, 1979) for a discussion of the notion of similarity that needs to be employed.

${ }^{27}$ I simplify considerably. See Ninan (2008) for a more detailed discussion. 
for sketching Ninan's puzzle. So, let us continue to frame things in terms of wish reports. Here is the problem. Ralph might wish that Ortcutt lived as a hermit, and was such that no-one ever bore any acquaintance relation to him. In this context, the report 'Ralph wishes that no-one ever bore any acquaintance relation to Ortcutt' is true and Ralph's wish is coherent. However, the obvious way of extending the descriptivist account to wish reports has Ralph wishing the impossible proposition, for whichever acquaintance relation is chosen, there is no world at which Ralph bears that relation to an object and no-one bears that relation to the object.

Ninan considers a descriptivist response to his puzzle that employs paired propositions. (He ultimately rejects this account because he rejects descriptivism. ${ }^{28}$ ) We will discuss this semantics in $\S 7$. For now, let us focus on the problem itself. It should be clear that although they both involve counterfactual attitudes, Ninan's puzzle is distinct from the problem raised by (2). Since Bill was not robbed, (2) cannot be read de re - our problem is not a problem of de re attitude ascriptions. Consequently, our puzzle doesn't only target descriptivists about the de re, and has broader scope than Ninan's. For instance, Ninan raises no problem for those who maintain that de re ascriptions involve singular propositions, i.e. structured propositions that contain the relevant object as a constituent. On this view, the proposition that Ralph wishes true contains Ortcutt as a constituent. By contrast, (2) raises a challenge for all popular precisifications of the Relational Analysis. Thus, it may be claimed that our problem is deeper than Ninan's, and brings out what is truly puzzling about counterfactual attitudes. ${ }^{29}$

\footnotetext{
${ }^{28}$ Ninan's preferred approach, which uses an enriched worlds framework, was mentioned briefly in fn.6.

${ }^{29}$ This is not to say that Ninan's discussion is of no interest. Indeed, he attempts to solve several difficult problems, e.g. so-called 'double vision' cases, that the present work does not touch on.
} 


\subsection{Maier's account}

I would also like to distinguish the proposal that I have developed from the account in (Maier, 2015). Although Maier isn't motivated by cases such as Burgled Bill, it is arguable that his account is able to handle reports such as (2). Maier employs a great deal of complex semantic machinery that I lack the space to present in detail here. In short, he uses a Discourse Representation Theory (DRT) framework in which each attitude type comes with its own Discourse Representation Structure (DRS). ${ }^{30}$ Referential dependencies between attitudes are captured by allowing presuppositions triggered in the DRS of one attitude to be accommodated in another. For instance, the presupposition triggered in a wish DRS can be accommodated in a belief DRS. Maier's theory can handle (2) because the sentence contains a presupposition trigger, namely a definite description. The description 'the person who robbed Bill' can be bound/accommodated in Bill's belief DRS. In this way, Maier can capture the fact that Bill's wish depends on his beliefs. ${ }^{31}$

One difference between Maier's account and my own comes out when we consider that the phenomenon of interest arises with a variety of DPs, not just those involving definites. For instance, there are true readings of both (22) and (23) in Burgled Bill:

(22) Bill wishes that every person who robbed him had never robbed anyone.

(23) Bill wishes that a person who robbed him had never robbed anyone.

Importantly, (23) shows that we can also get the puzzle going with non-presuppositional determiners — 'a person who robbed Bill' is not traditionally taken to be a presupposition trigger. ${ }^{32}$ So, Maier's account doesn't

\footnotetext{
${ }^{30}$ See (Geurts et al., 2016) for an introduction to DRT.

${ }^{31}$ Maier employs a Ninan (2008)-inspired two dimensional semantics for all counterfactual attitudes. I argue that this semantics is problematic in $\S 7$.

${ }^{32}$ One way to test whether a determiner is presuppositional is by embedding it under various
} 
predict that these DPs can be bound/accommodated in Bill's belief DRS. ${ }^{33}$

In response, an anonymous reviewer questions whether the indefinite in (23) is really non-presuppositional. Indefinites are known to have 'specific' readings, and some theorists have modeled this behavior in terms of presupposition. ${ }^{34}$ The idea is that Maier could take such a theory on board and claim that the indefinite in (23) is specific on the relevant reading.

However, one can construct cases where it is implausible that the indefinite is being read specifically. Consider a variant of Burgled Bill where Bill thinks that two people burgled him, but for various reasons wishes that only one of them had not done so. Suppose, for instance, that Bill's (idiosyncratic) insurance policy stipulates that he is entitled to a rebate only if he is burgled by exactly one person. In such a scenario, (23) is still true, but the criteria used to test for specificity suggest that the indefinite needn't be read specifically. ${ }^{35}$ Moreover, it is fair to say that the semantics of specificity is a controversial area. It is a mark against Maier's theory that it is hostage to the outcome of a hotly disputed topic. ${ }^{36}$

Notice that my account can handle (23) easily. We can give it the following LF:

(24) $\lambda w_{1}$ Bill wishes $_{w_{1}}\left[\lambda w_{2} \lambda w_{3}\right.$ a person-who-robbed-Bill $w_{2}$ never-robbed-anyone $\left.w_{3}\right]$

Given a standard semantics for the indefinite, (24) is true at $w_{@}$ just in case for

operators, e.g. negation and questions, and seeing if relevant material 'projects'. For instance, both 'It's not the case that the person who robbed Bill works in marketing' and 'Does the person who robbed Bill work in marketing?' entail that a unique person robbed Bill. This suggests that 'the person who robbed Bill' is a presuppositional determiner. By contrast, neither 'It's not the case that a person who robbed Bill works in marketing' nor 'Does a person who robbed Bill work in marketing?' entail that someone robbed Bill.

${ }^{33}$ Thanks to Daniel Rothschild for helpful discussion of this point.

${ }^{34}$ See (Hawthorne \& Manley, 2012, ch.4) for a good discussion of specific indefinites. See (van Greenhoven, 1998), (Geurts, 1999), and (Jäger, 2007) for presupposition-based theories of specificity.

${ }^{35}$ For instance, Bill needn't have any particular burglar 'in mind'.

${ }^{36}$ Further criticisms of Maier (2015)'s account are presented in (Blumberg, 2017). 
every one of Bill's belief worlds $w^{\prime}$, each world $w^{\prime \prime}$ that is maximally similar to $w^{\prime}$ in which someone who robbed Bill at $w^{\prime}$ never robbed anyone is such that Bill prefers $w^{\prime \prime}$ to $w^{\prime}$ at $w_{@}$. These truth conditions are intuitively adequate.

\section{Other counterfactual attitudes}

So far, we have focused on wish reports. However, it appears that we can construct variants of Burgled Bill with other counterfactual attitudes, e.g. 'imagine' and 'dream'. For instance, it is arguable that we can contrive a scenario in which there is a true reading of $(25)$ :

(25) Bill is imagining that the person who robbed him never robbed anyone.

As before, it is difficult to see what proposition Bill could be 'imagine'-related to here. How are we to capture such a report? There is a temptation to use paired propositions, just as we did in the case of 'wish'. But there is a

difficulty: 'imagine', unlike 'wish', is a representational attitude. That is, it does not involve any notion of preference over alternatives. This is rather obvious, but just to be sure, notice that 'imagine' is monotonic over relevant logical consequences: (26) does entail (27).

(26) Bill imagined that both coins landed heads.

(27) Bill imagined that the second coin landed heads.

Thus, the comparative desirability semantics developed in $\S 6$ cannot be adapted to 'imagine'.

What, then, should be done about representational counterfactual attitudes? As far as I am aware, the only existing approach that is relevant is the account mentioned in $§ 6.5$; a semantics developed, but ultimately rejected, by Ninan 
(2008). ${ }^{37}$

On this semantics, imagination content is modeled in terms of paired propositions. The fundamental notion is the following: a pair of worlds $\left\langle w^{\prime}, w^{\prime \prime}\right\rangle$ is compatible with what $x$ imagines in $w$ iff: $w^{\prime}$ is compatible with what $x$ believes in $w$, and $w^{\prime \prime}$ is compatible with what $x$ imagines in $w$ relative to $w^{\prime} .(25)$ is true at $w @$ just in case for every one of Bill's belief worlds $w^{\prime}$, and every world $w^{\prime \prime}$ compatible with what Bill imagines at $w @$ relative to $w^{\prime}$, the person who robbed Bill in $w^{\prime}$ never robbed anyone in $w^{\prime \prime}$.

Whether the above truth-conditions are adequate ultimately depends on our ability to make sense of the notion of 'relative compatability', i.e. compatability of an imagination alternative relative to a belief world. Although several theorists have made use of this concept, e.g. Yanovich (2011) and Maier (2015), it is not at all clear to me that we have a satisfactory grip on it.

Ninan (2008, 42-43) suggests that we can get an intuitive grasp of it by leaning on the familiar notion of a single world $w^{\prime \prime}$ being compatible with what a subject imagines. We should think about what a subject's imagination-worlds would be like if the subject was maximally opinionated, i.e. if, at $w, x$ 's belief set was a singleton containing $w^{\prime}$. In other words, $w^{\prime \prime}$ is compatible with what $x$ imagines in $w$ relative to one of her belief worlds $w^{\prime}$ just in case if $w^{\prime}$ had been $x$ 's only belief world, then $w^{\prime \prime}$ would have been compatible with what $x$ would have imagined.

However, Ninan's counterfactual gloss doesn't make the notion any clearer. ${ }^{38}$ On this gloss, (25) is true at $w_{@}$ just in case for every one of Bill's belief worlds $w^{\prime}$, if $w^{\prime}$ had been Bill's only belief world, then every world $w^{\prime \prime}$ compatible with

\footnotetext{
${ }^{37}$ As mentioned in $\S 6.5$, Ninan develops a semantics for de re imagination reports. However, (25) cannot be read de re. Thus, strictly speaking the account I present is a variant of Ninan's theory.

${ }^{38}$ When Yanovich and Maier attempt to justify their use of the notion, they simply repeat Ninan's counterfactual gloss.
} 
what Bill would have imagined is one where the person who robbed Bill in $w^{\prime}$ never robbed anyone in $w^{\prime \prime}$. However, if Bill's beliefs were different, there is no saying which worlds would have been compatible with what he would have imagined. For instance, if $w^{\prime}$ - a world in which Joe robs Bill — had been Bill's only belief world, then every world $w^{\prime \prime}$ compatible with what Bill would have imagined could have been one where Joe robs him. Perhaps when Bill is certain about the identity of the thief, the only worlds compatible with what Bill imagines are ones where the thief robs him. In that case, (25) can still be true, but Ninan's gloss suggests that it should be false.

Indeed, if Bill had been sure about the identity of the culprit, then perhaps we can't even coherently ask which worlds would have been compatible with what he would have imagined. Bill might have been too distracted trying to catch the thief to have engaged in any sort of imagination episode. In short, the prospects of cashing out Ninan's notion of relative compatability in counterfactual terms are pretty dim.

A comparison with the account of 'wish' developed in $\S 6$ is helpful. The central notion employed there involved a subject's preference for one state of affairs over another. I take it that we have a reasonably good grasp of this. Moreover, it gives us insight into the meaning of 'wish': when a subject wishes something, they appear to be in the same state as thinking that it would be better if that thing holds. Our semantics captures that fact. By contrast, Ninan's notion of 'relative compatability' appears to be a mere technical device that obscures, rather than aids, our understanding of 'imagine'.39

\footnotetext{
${ }^{39}$ In fairness to Ninan, after giving his gloss he says that it shouldn't be taken too seriously and is 'really just a heuristic for getting an intuitive grip on what...we should regard as a primitive notion in our theory of imagining' (Ninan, 2008, 43). Of course, some concepts need to be taken for granted in any semantic theory. But it is far too early in our theorizing about counterfactual attitudes to take a notion such as relative compatability as a primitive. The thing that is puzzling about reports such as (25) is that Bill's beliefs seem to play an important role in his imagination episode. This is what we must explain. However, taking the notion of relative compatability as primitive does not satisfy this explanatory need.
} 
To sum up, there is an inclination to employ paired propositions in our semantics for 'imagine' (and 'dream'), just as we did with 'wish'. However, it is unclear how this is to be done. Since such attitudes are representational, they cannot be given a comparative desirability semantics analogous to the one that we have developed for 'wish'. Moreover, the only semantics that has been developed for such attitudes employs a notion that is opaque at best. ${ }^{40}$

\section{The Relational Analysis again}

In $\S 7$ we considered some of the challenges of giving counterfactual attitude verbs a uniform analysis in the sense of them all expressing relations that hold between subjects and paired propositions. Let us put those difficulties to one side and suppose that a uniform analysis of counterfactual attitude verbs is attainable. Given this assumption, a uniform analysis of attitude verbs in general is not too far away. For instance, we can raise the type of attitude verbs that do plausibly relate subjects to sets of worlds, e.g. 'believe', quite easily by essentially ignoring one of the worlds in each pair. ${ }^{41}$

\footnotetext{
${ }^{40}$ Some might be tempted to model (25) by supposing that a subject's imagination episode determines a set of worlds $\operatorname{Img}_{w, x}$, and that paired propositions constrain this set by taking the subject's belief worlds as arguments. A more formal representation of this idea is (28):

(28) imagine $\rrbracket=\lambda w \in D_{s} . \lambda p^{*} \in D_{\langle s,\langle s, t\rangle\rangle} . \lambda x \in D_{e} . \operatorname{Img}_{w, x} \subseteq \bigcup\left\{p^{*}\left(w^{\prime}\right) \mid w^{\prime} \in \operatorname{Dox}_{w, x}\right\}$ However, this account overgenerates. Consider a scenario where Bill thinks that either Joe or Steve robbed him, but he is not sure which. Furthermore, suppose that Bill thinks that one of them stood guard. Bill says 'I'm imagining that the person who stood guard stayed at home'. The set of Bill's suspects for robbing him is identical to the set of his suspects for standing guard, namely \{Joe, Steve\}. Thus, (28) predicts that 'Bill is imagining that the person who stood guard stayed at home' is true iff 'Bill is imagining that the person who robbed him stayed at home' is. But intuitively the latter report is false in this context. Thanks to Cian Dorr and Philippe Schlenker for discussion here.

${ }^{41}$ Type-raising of this sort was pioneered by Montague, who, for example, raised the type of names and pronouns to generalized quantifiers. Ignoring the first element in each pair, 'believe' can take the following meaning:

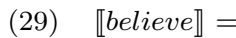

$$
\lambda w \in D_{s} . \lambda p^{*} \in D_{<s,<s, t>>} . \lambda x \in D_{e} . \operatorname{Dox}_{w, x} \subseteq\left\{w^{\prime \prime}:\left\langle w^{\prime}, w^{\prime \prime}>\in p^{*}\right\}\right.
$$

A sentence such as 'Bill believes that Ann left' will receive the following LF:

(30) $\lambda w_{1}$ Bill believes $_{w_{1}}\left[\lambda w_{2} \lambda w_{3}\right.$ Ann left $\left._{w_{3}}\right]$
} 
The question I want to address is whether a uniform analysis of attitude verbs (in terms of paired propositions) vindicates a precisification of the Relational Analysis. Most importantly, whether paired propositions could serve as a precisification of the notion of 'proposition'.

Any worthwhile notion of 'proposition' needs an attendant notion of when such propositions are true. Let us say that a paired proposition $p^{*}$ is true at a world $w$ just in case $\langle w, w\rangle \in p^{*}$.

However, even granting the above notion of truth, my sense is that the problem that reports such as (2) pose for the Relational Analysis is robust. Even if we are able to give a uniform analysis of attitude verbs, (2) doesn't appear to be equivalent to either (31) or (32):

(31) That the person who robbed Bill had never robbed anyone is something Bill wishes were true.

(32) That the person who robbed Bill never robbed anyone is something Bill wishes were true.

Besides de re readings that require that there be someone who robbed Bill, the only coherent readings of (31) and (32) are 'temporal' ones, which have Bill wishing that the person who robbed him didn't rob anyone in the past, before they robbed Bill. But if the Relational Analysis holds, then we would expect (2) and at least one of (31) or (32) to have the same range of readings. ${ }^{42}$

This argument is not decisive, but it does show that even if attitude verbs can be given a uniform analysis in terms of paired propositions, more work needs to be done in order to defend the Relational Analysis.

On this system, (30) is true at $w_{@}$ just in case Bill's belief set in $w_{@}$ is a subset of the set of worlds in which Ann left, i.e. for every one of Bill's belief worlds $w^{\prime}$, Ann left in $w^{\prime}$. Thus, the truth conditions obtained are the same as those generated by the Hintikka-style semantics of $\S 3$.

${ }^{42}$ I include (32) because some might complain that (31) is problematic due to a syntactic matter involving the licensing of the 'fake past tense'. Thanks to Cian Dorr for discussion of this point. 


\section{Conclusion}

I have argued that standard precisifications of the Relational Analysis are inadequate. Others have done the same. For instance, it has been maintained that although it is necessary for the truth of ' $S \Phi$ s that P' that $S$ stands in the $\Phi$-relation to the proposition that $\mathrm{P}$, it is not sufficient, since there are other conditions on the truth of such reports as well. ${ }^{43}$ Meanwhile, some hold that the truth of ' $S \Phi$ s that $\mathrm{P}$ ' requires that $S$ stands in the $\Phi$-relation to a proposition, but not necessarily the proposition that $\mathrm{P} .{ }^{44}$ Although these critics reject popular accounts of the Relational Analysis, they still think that the proposition that $\mathrm{P}$, or some other proposition - where 'proposition' is given a standard meaning - plays an important role in determining the truth-value of the relevant attitude report. By contrast, I have argued that there are cases where no orthodox proposition plays any role in determining the truth-value of the relevant report. In this sense, my criticism of standard precisifications of the Relational Analysis is more radical than those that have come before.

Although standard accounts of the Relational Analysis struggle with wish reports, I have tried to show that the prospects for an account on which these reports relate subjects to sets of pairs of worlds - what I call paired propositions - rather than just sets of worlds seem to be good. However, it is unclear whether paired propositions can be employed to give a uniform analysis of attitude verbs, and if so, whether this vindicates a particular precisification of the Relational Analysis. These are areas for future work. ${ }^{45}$

${ }^{44}$ E.g. Graff Fara (2013). Graff Fara puts quite strict constraints on the proposition to which $S$ is $\Phi$-related: she maintains that this proposition must entail the proposition that $\mathrm{P}$. It is arguable that Bach (1997) holds a similar view.

${ }^{45}$ Earlier versions of this paper were presented at the New York Philosophy of Language Workshop, the NYU Washington Square Circle seminar, and the NYU Thesis Preparation seminar in the spring of 2016. I'd like to thank all of the participants at those presentations for their feedback. I'd also like to thank Jeremy Goodman, Gary Ostertag, Daniel Rothschild,
} 


\section{References}

Bach, Kent. 1997. Do Belief Reports Report Beliefs? Pacific Philosophical Quarterly, 78(3), 215-241.

Blumberg, Kyle. 2017. Parasites. NYU.

Bolinger, Dwight. 1968. Postposed main phrases: an English rule for the Romance subjunctive. Canadian Journal of Linguistics/Revue canadienne de linguistique, 14(9), 3-30.

Braun, David. 2008. Persisting Problems for a Quantificational Theory of Complex Demonstratives. Philosophical Studies, 141(3), 243-262.

Crimmins, Mark, \& Perry, John. 1989. The Prince and the Phone Booth:

Reporting Puzzling Beliefs. Journal of Philosophy, 86(12), 685-711.

Elbourne, Paul. 2013. Definite Descriptions. Oxford University Press.

Farkas, Donka F. 1992. On the Semantics of Subjunctive Complements. Pages 69-105 of: Hirschbühler, Paul, \& Koerner, E.F.K. (eds), Romance Languages and Modern Linguistic Theory. John Benjamins.

Fine, Kit. 1975. Critical Notice of Lewis, Counterfactuals. Mind, 84(335), $451-458$.

Geurts, Bart. 1999. Specifics. Pages 99-109 of: Geurts, B., Krifka, M., \& van der Sandt, R. (eds), Focus and Presupposition in Multi-speaker Discourse. Universiteit Utrecht.

Philippe Schlenker and Yael Sharvit for helpful discussion of various points. Chris Barker, Ben Holguin, Harvey Lederman, Jim Pryor, and Stephen Schiffer read earlier drafts of the paper, and their input improved the final product significantly. I am also indebted to two anonymous reviewers at Mind who provided much constructive criticism and made many helpful suggestions. Finally, I'd especially like to thank Cian Dorr for reading numerous drafts and providing valuable feedback at every stage of the paper's development. 
Geurts, Bart, Beaver, David I., \& Maier, Emar. 2016. Discourse Representation

Theory. In: Zalta, Edward N. (ed), The Stanford Encyclopedia of Philosophy, spring 2016 edn.

Graff Fara, Delia. 2013. Specifying Desires. Noûs, 47(2), 250-272.

Hawthorne, John, \& Manley, David. 2012. The Reference Book. Oxford University Press.

Heim, Irene. 1992. Presupposition Projection and the Semantics of Attitude Verbs. Journal of Semantics, 9(3), 183-221.

Heim, Irene, \& Kratzer, Angelika. 1998. Semantics in Generative Grammar. Blackwell.

Hintikka, Jaakko. 1962. Knowledge and Belief. Ithaca: Cornell University Press.

Jäger, Gerhard. 2007. Partial Variables and Specificity. London: Palgrave Macmillan UK. Pages 121-162.

Keshet, Ezra. 2008. Good Intensions: Paving Two Roads to a Theory of the De re/De dicto Distinction. Ph.D. thesis, Massachusetts Institute of Technology.

King, Jeffrey C. 2014. Structured Propositions. In: Zalta, Edward N. (ed), The Stanford Encyclopedia of Philosophy, spring 2014 edn.

Lewis, David. 1979. Attitudes de Dicto and de Se. Philosophical Review, 88(4), $513-543$.

Lewis, David. 1979. Counterfactual Dependence and Time's Arrow. Noûs, 13(4), 455-476.

Lewis, David K. 1973. Counterfactuals. Blackwell.

Maier, Emar. 2015. Parasitic Attitudes. Linguistics and Philosophy, 38(3), $205-236$. 
Ninan, Dilip. 2008. Imagination, Content, and the Self. Ph.D. thesis, Massachusetts Institute of Technology.

Ninan, Dilip. 2012. Counterfactual Attitudes and Multi-Centered Worlds. Semantics and Pragmatics, 5(5), 1-57.

Percus, Orin. 2000. Constraints on Some Other Variables in Syntax. Natural Language Semantics, 8(3), 173-229.

Romoli, Jacopo, \& Sudo, Yasutada. 2009. De Re/De Dicto Ambiguity and Presupposition Projection. Proceedings of Sinn und Bedeutung 13, 425-438.

Rubinstein, Aynat. 2012. Roots of Modality. Ph.D. thesis, University of Massachusetts Amherst.

Salmon, Nathan. 1998. Nonexistence. Nô̂s, 32(3), 277-319.

Schiffer, Stephen R. 2003. The Things We Mean. Oxford University Press.

Schoubye, Anders Johan. 2013. Ghosts, Murderers, and the Semantics of Descriptions. Nô̂s, $\mathbf{4 7}(3)$, 496-533.

Soames, Scott. 2002. Beyond Rigidity: The Unfinished Semantic Agenda of Naming and Necessity. Oxford University Press.

Stalnaker, Robert. 1984. Inquiry. Cambridge University Press.

Stalnaker, Robert. 1988. Belief Attribution and Context. Pages 140-156 of: Grimm, Robert H., \& Merrill, D. D. (eds), Contents of Thought. University of Arizona Press.

van Greenhoven, Veerle. 1998. Semantic Incorporation and Indefinite Descriptions. CSLI Publications, Stanford.

Villalta, Elisabeth. 2008. Mood and Gradability: An Investigation of the Subjunctive Mood in Spanish. Linguistics and Philosophy, 31(4), 467-522. 
von Fintel, Kai, \& Heim, Irene. 2011. Intensional Semantics. MIT unpublished class notes.

Yanovich, Igor. 2011. The problem of counterfactual de re attitudes. Semantics and Linguistic Theory, 21, 56-75. 